\title{
Light emitting diode vs fluorescent considerations in public and commercial lighting applications.
}

\author{
J Swanepoel $^{1}$, E. Chikuni ${ }^{2}$, Henk van de Merwe $^{3}$ \\ jswanepoel@gibb.co.za, echikuni@ieee.org \\ ${ }^{1}$ Cape Peninsula University of Technology, \\ ${ }^{2}$ Department of Electrical Engineering, University of Zimbabwe \\ ${ }^{3}$ Gibb, Cape Town
}

\begin{abstract}
The purpose of this paper is to compare the two most efficient lighting technologies available today for general and indoor applications. LED lighting with its unmatched energy efficacy and flexibility and fluorescent lighting with its affordability and matured technology will be tested in two case studies with the aid of a lighting simulation tool Relux, along with a feasibility study to form a conclusive comparison between fluorescent and LED lighting.
\end{abstract}

Keywords: CFL bulbs; LED bulbs; savings; power consumption; electricity bills; RELUX

\section{Introduction}

With the ever growing electrical load on the national grid and constant electricity price increases both past and present it becomes important to look at ways to not only lower the electrical demand but also look at ways to save electricity at home or for a business and avoid unnecessarily costs. One such way is to utilize energy efficient lighting. The ever constant debate of 'light emitting diode' (LED) lighting being the future of lighting and replacing fluorescent and other lighting sources in both domestic and commercial applications to become the worlds most used lighting technology is at the forefront of every lighting manufactures sales pitch. Every lighting designer has to carefully consider these two lighting sources and every time comparisons have to be made to see which gives the best solution from both a technical and aesthetical point of view. Also, factors such as capital cost, maintenance cost and life cycle have to be considered. Currently the market share of the lighting is at 56\% for fluorescent and $12 \%$ for LED respectively, a statistic that is estimated to change dramatically in the years to come [1].

Despite the superior energy saving qualities that LED fittings possess, it is still uncertain as to when LED fittings will flood the market. This is due to the high production and retail cost attached to these LED light fitting along with inferior colour rendering and less luminous output compared to other lighting technologies. Adding to this pressure on LED lighting is constant development from fluorescent lighting, development such as the introduction of the T5 lamp, a lamp that is very energy efficient. It also does not help being such a new lighting technology with very little research available and market uncertainty compared to other lighting technologies that's been around since the invention of the light lamps in the early

ACRID 2017, June 20-21, Victoria Falls, Zimbabwe

Copyright $(2017$

DOI 10.4108/eai.20-6-2017.2271000 
1800s. [2]. It could be argued that solid-state lamps have been around for long enough but that was for applications where high efficiency was important and at low power levels, for example in applications such as flashlights, solar powered devices and traffic lights. Although constantly improving and evolving mainly in more recent times it becomes obvious that there have been massive progression in LED lighting development minimizing its shortcomings. Aided with leading luminaire manufactures embracing the new technology and with their own brand awareness LED lighting systems are slowly receiving industry approval. It is hoped that the results in this paper will help shed some light on these matters.

\section{Methodology}

Two case studies were conducted using the Relux $@$ modelling software.

\subsection{Case Study 1:}

A Relux simulation based on Matlosana malls undercover parking area. The undercover parking consists of around 760 parking bays and in the region of $21,360 \mathrm{~m}^{2}$. The mall, based in Klerksdorp, has just started construction. The lighting design criteria for the undercover parking is a vapour proof type fitting between every second parking bay thus around 1 fitting for every $30 \mathrm{~m}^{2}$ with a minimum of 75 lux on floor surface to be achieved as per the 'South African national standards' (SANS) [3] . A separate traffic lane count was not conducted, but observed to ensure that more than the minimum of 75 lux was achieved. A total of 680 light fittings where used for the LED vs fluorescent lighting comparison, the same amount for both technologies. The LEDVP from LEDSA and the Lascon C2F-N-149ELB was used with the energy consumption based around an average weekday baseline of $100 \%$ of fittings burning between $06 \mathrm{~h} 00 \mathrm{am}$ to $12 \mathrm{~h} 00 \mathrm{pm}$ Monday to Sundays and with $30 \%$ lighting burning for 24 hours at $123.00 \mathrm{c} / \mathrm{kWh}$ based on the current business rate from the local authority in this case Eskom [4]. 


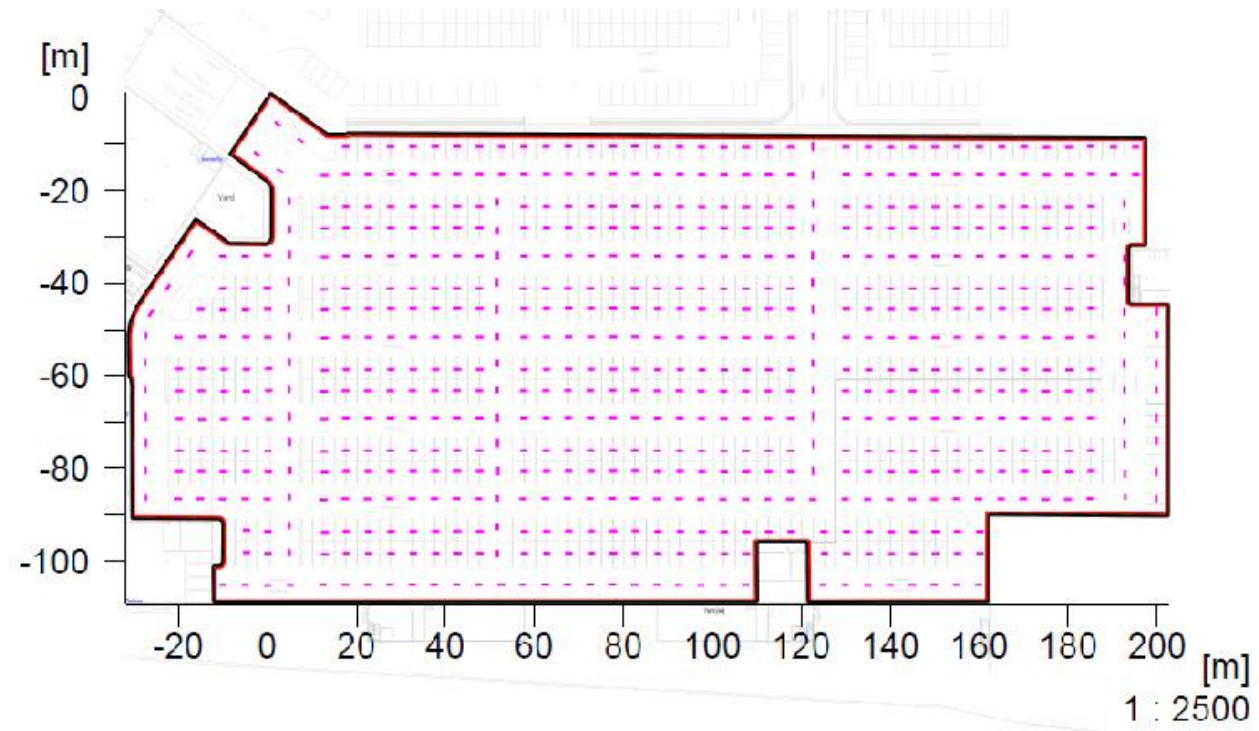

\subsection{Case study 2:}

Fig. 1. Under Cover Parking Layout

A Relux $@$ simulation of an office open plan of $500 \mathrm{~m}^{2}$ for commercial purpose. The design criteria are to achieve 500 lux measure on the work surface, thus $750 \mathrm{~mm}$ above the floor. The LEDVT from LEDSA and the Lascon RCB-254 was used to form a realistic and competitive comparison of current industry used light fittings. The energy consumption calculation for the office was based around an average weekday baseline of $100 \%$ of fittings burning between $07 \mathrm{~h} 00$ am to $8 \mathrm{~h} 00 \mathrm{pm}$ Monday to Fridays and with $10 \%$ of the lighting staying on $24 \mathrm{hours}$ at $123.00 \mathrm{c} / \mathrm{kWh}[4]$.
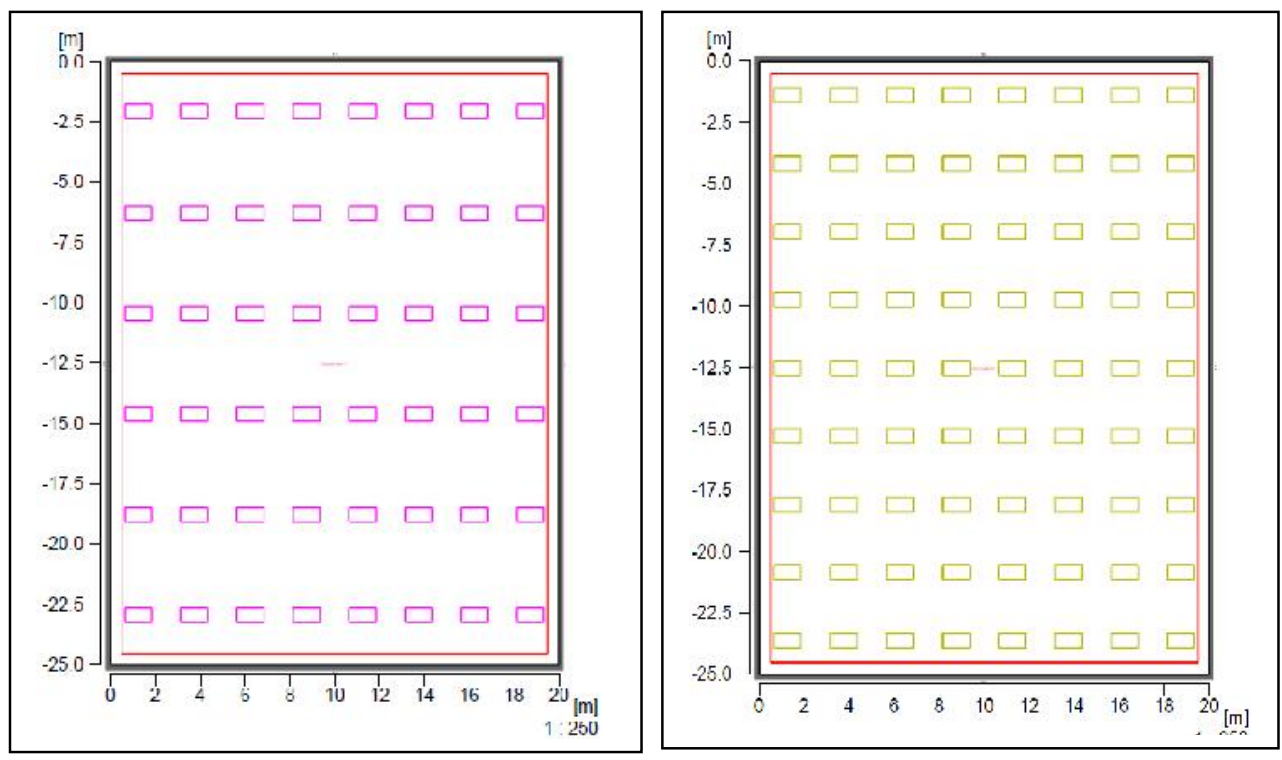


\section{Fig. 2.}

Relux fluorescent fitting layout on left and LED fitting on thr right calculated at 500 lux. Due to the LED's lesser luminous efficacy it can be observed that the LED lighting layout consists of 72 light fittings' compared to the 48 light fittings of fluorescent to achieve an average of around 500 lux..

\section{Results}

\subsection{Case study 1:}

With the light fittings specifically chosen to comply with the SANS 1114-1 and as current industry utilized, it can be observed that the calculated Relux model indicating an average lux level of 98.5 lux for fluorescent fittings and 75 lux for the LED fittings. Figure 3 and 4 illustrate the area luminance spread over the entire parking area. It can be observed that LED fittings are very directional where fluorescent fittings gives off a much more even spread due to the lamps illuminating an 360 degree orbit with a wide reflector. Both these designs achieved the required design criteria with fluorescent marginally better

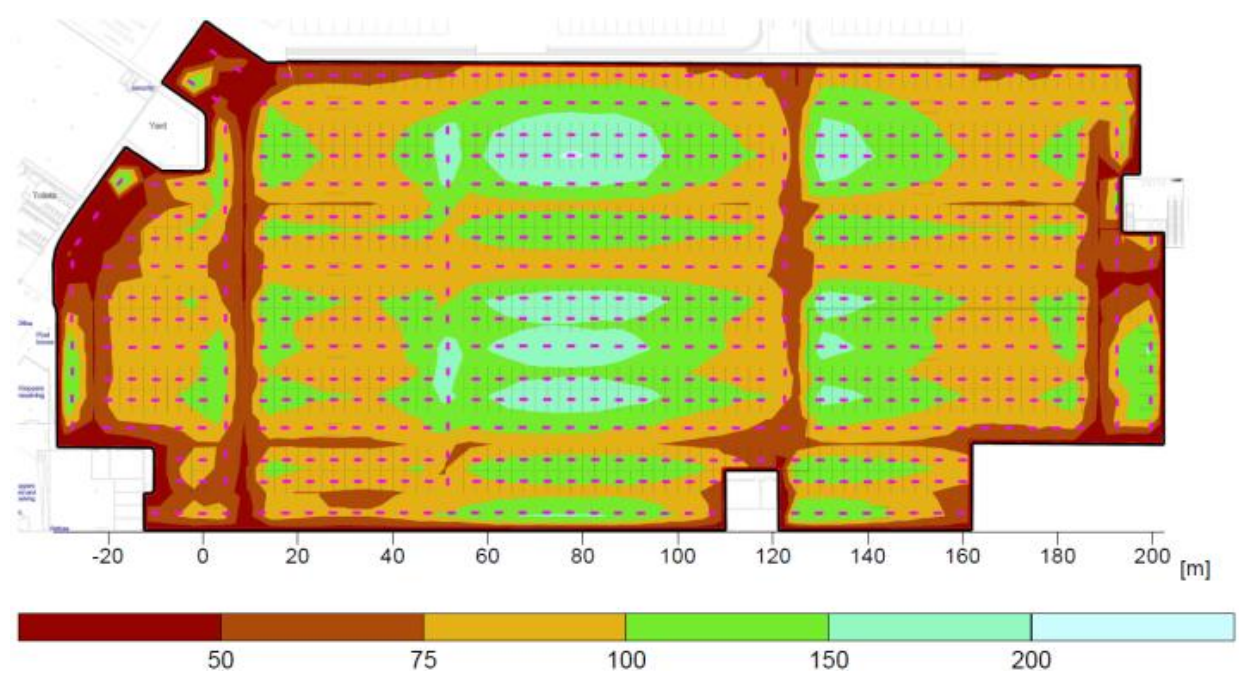

Fig. 3. Relux Illuminated Models for LED fittings, Area 1 


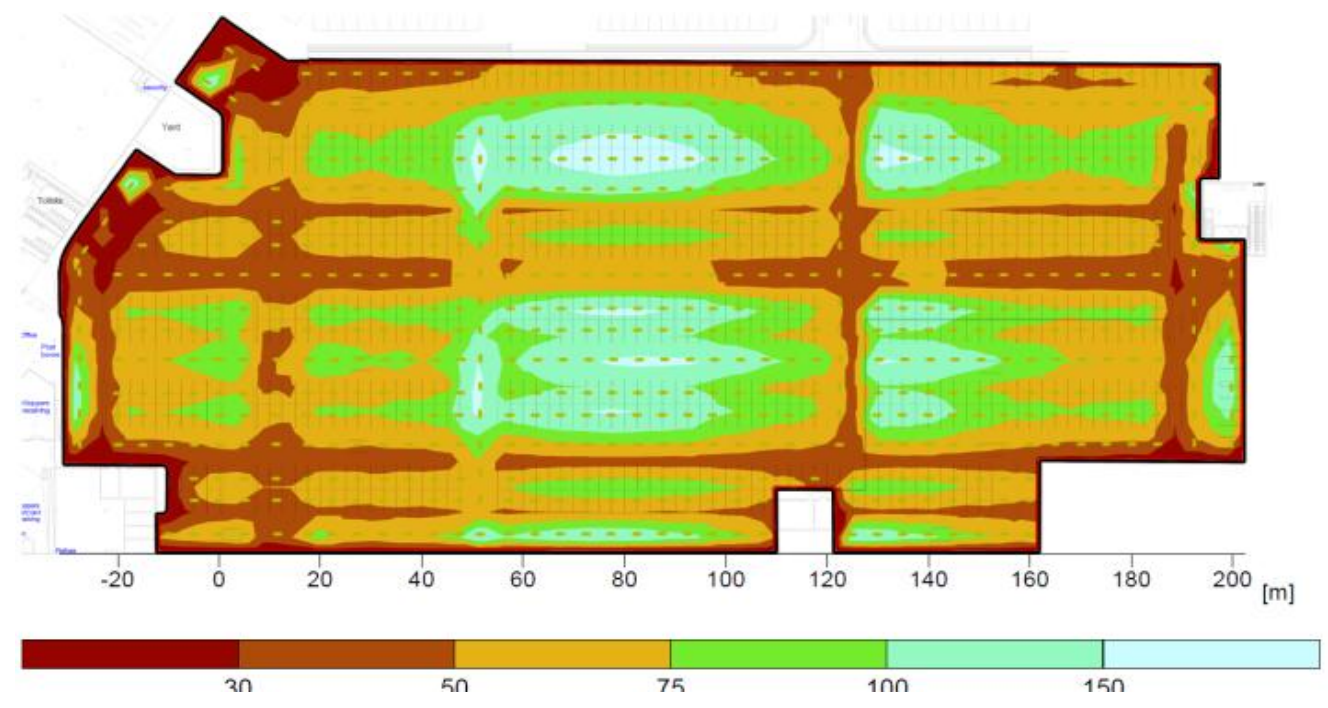

Fig. 4. Relux Illuminated Models for LED fittings, Area 2

LED lighting's strong point is their efficiency, Figure 5 indicates the difference in daily power consumption with the hatched area between the LED and fluorescent line being the saving in electricity from the LED fittings. Relux calculated the electrical consumption of the LED fitting at $1.27 \mathrm{~W} / \mathrm{m}^{2}$ and the electrical consumption of the fluorescent fitting at $1.73 \mathrm{~W} / \mathrm{m}^{2}$.

The hand calculated difference in daily power consumption between fluorescent lighting and LED lighting is $27.2 \mathrm{~kW}$ and $33.3 \mathrm{~kW}$ respectively, an $18,3 \%$ difference in daily power consumption.

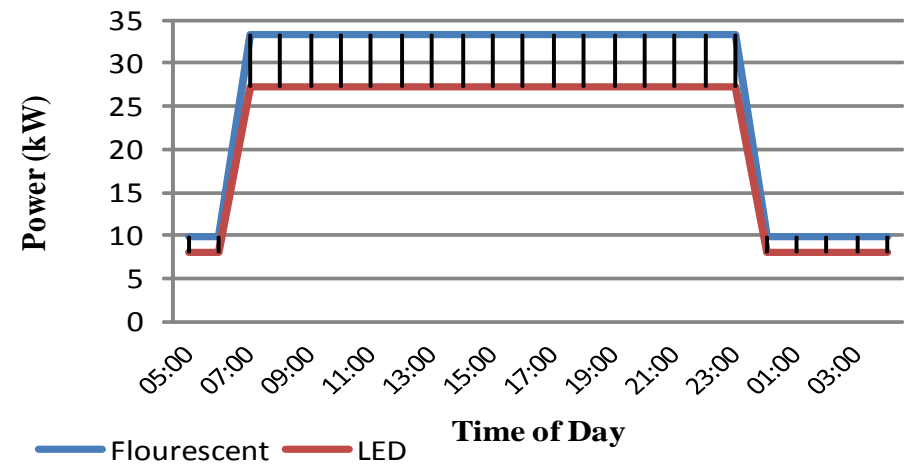

\subsection{Case study 2:}

Fig. 5. Average daily power consumption comparison

The Relux design criteria were to achieve an average of around 500 lux as per the SANS 1114-1 regulation for commercial office space with glare and light pollution not considered to simplify calculations. The light fitting selected is industry proven and very current. Figure 6 shows the lighting layout required to achieve a 500lux overall, with LED requiring an additional 24 light fitting to achieve the same requirements, but ahead in the power consumption with $6.48 \mathrm{~W} / \mathrm{m}^{2}$ for LED light fittings and $10.37 \mathrm{~W} / \mathrm{m}^{2}$ for fluorescent light fittings. Below this is the colour bar used to see the luminance per area or zone. 
Fig. 6. Relux illuminated model for fluorescent fitting on left and LED light fitting on right calculated around 500 lux

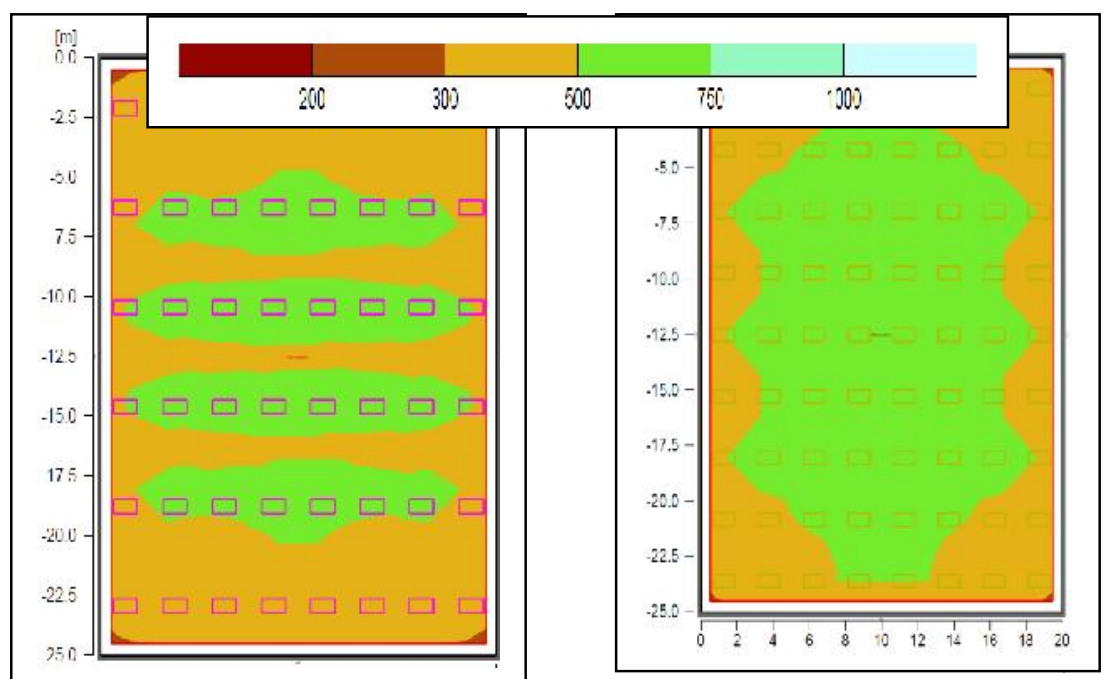

Fig. 6. Relux illuminated model for fluorescent fitting on left and LED light fitting on right calculated around 500 lux

Figure 7 indicates the difference in daily power consumption with the hatched area between LED and fluorescent being the saving in electricity from the LED fittings. Relux calculated the electrical consumption of the LED fitting at $6.48 \mathrm{~W} / \mathrm{m}^{2}$ and the electrical consumption of the fluorescent fitting at $10.37 \mathrm{~W} / \mathrm{m}^{2}$.

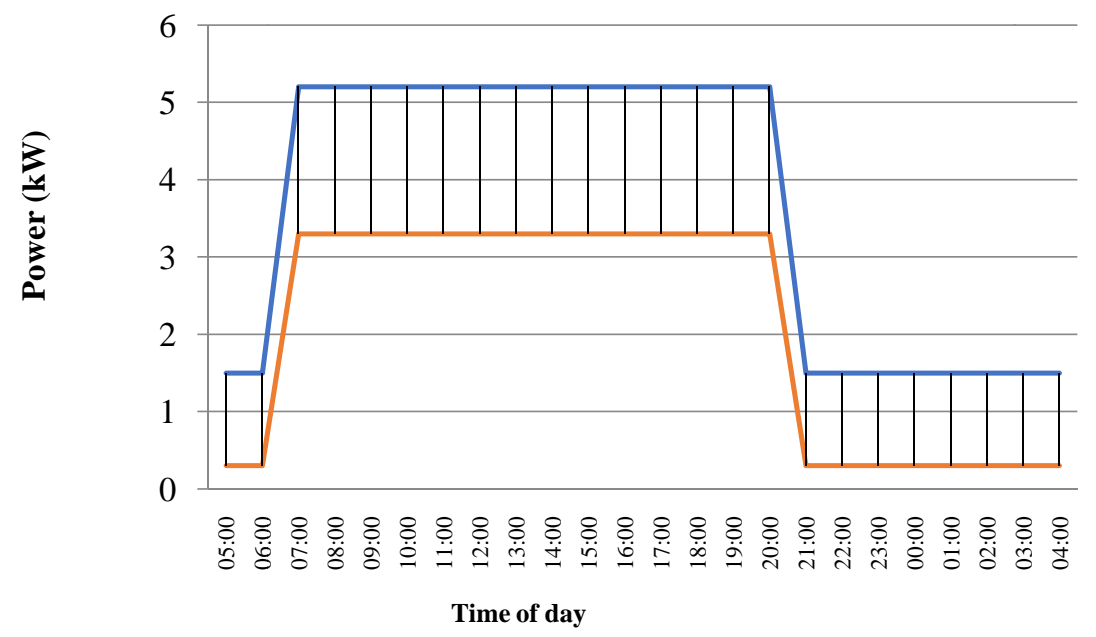

- Flourescent

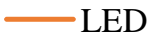

Fig. 7. LED Average Daily Power Consumption 
The hand calculated difference in daily power consumption for LED lighting is $2.88 \mathrm{~kW}$ and $5.18 \mathrm{~kW}$ for fluorescent lighting respectively, an $44.4 \%$ difference in daily power consumption.

Normal

\section{Financial Analysis}

\subsection{Case study 1:}

For the financial analysis it is important to take all factors into consideration such as electricity saved, capital cost, lamp life, re-lamping, labour cost and even correct disposal of fluorescent lamps as it contains mercury vapour.

Table 1.Financial cost taken into consideration for feasibility calculation

\begin{tabular}{llll}
\hline & Unit Cost & Replacement cost per unit & Disposal of lamps per unit \\
\hline LED & R1150.00 & R0.00 & R0.00 \\
Fluorescent & R450.00 & R60.00 & R5.00 \\
\hline
\end{tabular}

A factor not considered into the analysis is the saving in electrical consumption to air conditioning due to LED lighting producing less heat than fluorescent lighting and with the undercover parking being naturally ventilated.

Figure 8 is based on initial capital cost, accumulative electrical consumption cost and maintenance cost over a period of 10 years. It gives an estimate of when the LED lighting design will break even compared to the fluorescent lighting design, based on the fact that LED lighting has a higher initial capital cost but an immediate saving in monthly electrical power consumption. Based on calculations the initial capital cost of LED fittings are three times more expensive with a R30 000.00 saving in electricity consumption per annum bringing the break-even point to around 4 years. The advantage of LED fitting is the superior lamp life of 50000 hours compared to 30000 hours of the fluorescent with re-lamping and maintenance cost effecting the fluorescent affordability. With most lamps burning around 9072 hours per year the LED lighting installation only needs to be replaced around the five and a half year mark. Along with the fluorescent lamps being re-placed before the 30000 hours due to a decreasing luminous level of fluorescent making the LED lighting installation slightly more affordable [5].

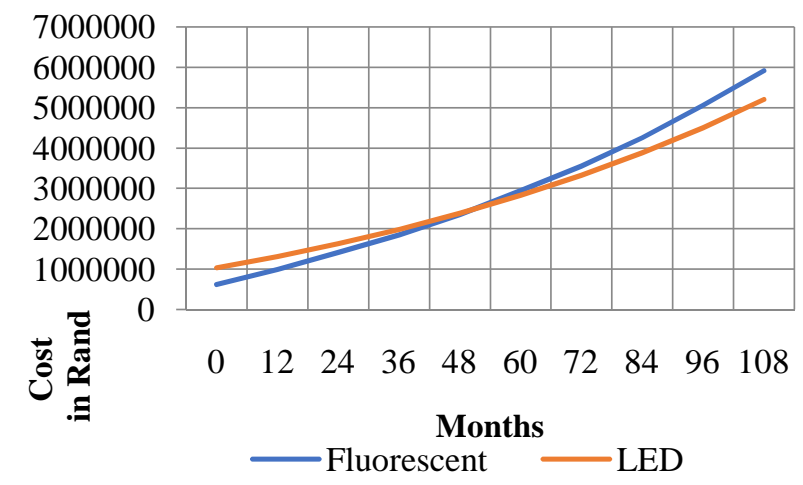


Fig. 8. Break-even point for undercover parking lighting installation

\subsection{Case study 2}

Figure 9 is based like in case 1 around the cost given in Table 1 over a period of 10 years. Based on calculations the initial capital cost of LED fittings is around twice the cost of fluorescent installation with a R12 000.00 saving in electricity consumption per annum bringing the break-even point between 2 and 3 years with the LED fitting lamp life of 50000 hours compared to 30000 hours of the fluorescent .

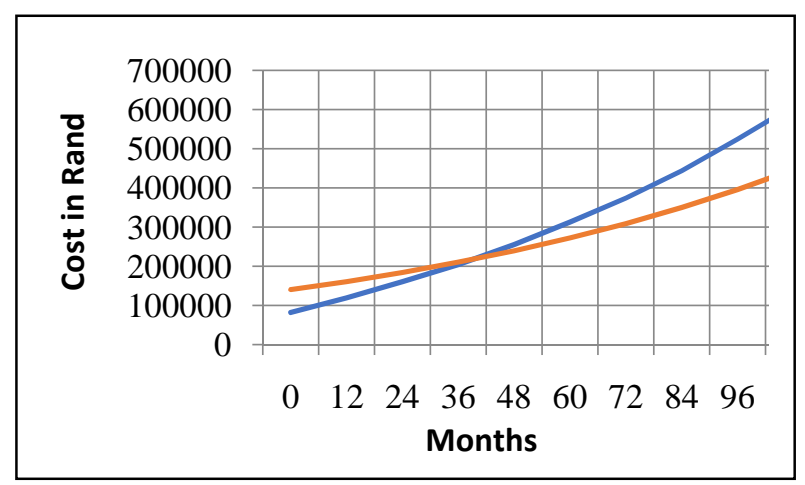

Fig. 9 Break-even point for office lighting installation

\section{Conclusions}

The case studies show that that LED lighting will continue to make inroads in to the modern lighting arena. LED lighting has longer lasting lamp life compared to fluorescent lighting, has greater energy-efficiency that will release pressure from the national grid and are more ergonomic than fluorescent lighting with fluorescent light being drab and flicker.

The feasibility comparison shows that LED unfortunately has a higher capital cost but that to some extend can be overlooked when considering the knock on effect to air conditioning due to less heat dispersion from LED lamps thus an additional saving in electrical consumption and with the break-even point around three to four year the LED lighting installation becomes more affordable. Also to be considered is that manufacturing costs of LED's are dropping with the now production of metal-coated silicon wafers instead of expensive sapphire-based bulbs.

LED lighting are low on maintenance compared to the low life of fluorescent due to burnout from frequent cycling, dimming of lamp and failing to start in cold or moist environments.

The deciding factor for the author is that LED lighting contains no harmful hazardous material such as the mercury contained in fluorescent lamps with huge emphasis on renewable energy and lowering the carbon footprint and along with manufacturing costs dropping as previously mentioned leaving no doubts that LED lighting are here to stay and is the future of lighting. 


\section{Acknowledgements}

A special thanks to Cornel Neethling from LEDSA and Richard Lowe from Bellco for providing product budget prices and technical data.

\section{References}

[1] L.Pinkerton.'The enormous LED opportunity".Internet: http://newenergynews.blogspot.com/2013/05/the-enormous-led-opportunity.html.May.14,2013 [Accessed 01 October 2013]

[2] M G. Farmer. "Eliot's Inventor".Internet: http://web.archive.org/web/20060619234400/http://eliotmaine.org/mosespage.htm. June.19, 2006. [Accessed 01 October 2013]

[3] Eskom - tariffs and charges.Internet: http://www.eskom.co.za/c/53/tariffs-and-charges/. [Accessed 01 October 2013]

[4] Interior Lighting (Part 1: Artificial Lighting of Interiors), South African Bureau of Standards, SABS 0114-1, 1996.

[5] B Rowell, Let there be light, RSA:EE Publishers (Pty) Ltd, 2002, pp.44-45 